is relevant to developing a better understanding of the complex nature of particles in urban street canyons and their relationship to pedestrian exposure at ground level.

To-date, studies investigating vertical profiles of particle mass concentrations around building envelopes has yielded inconsistent findings. Some research concluded that concentrations decreased with increasing height, including Horvath et al. (1988) who showed that diesel particle mass concentration decreased by $17 \%$ at $27 \mathrm{~m}$ compared to street level. Micallef and Colls (1998) found that $\mathrm{PM}_{10}$ and total suspended particle (TSP) concentrations at a height of $0.8 \mathrm{~m}$ above the ground floor were about $35 \%$ higher than those at a height of $2.9 \mathrm{~m}$, while Rubino et al. (1998) reported a decrease in the concentrations of $\mathrm{PM}_{10}$ with increasing height, and the concentration on the leeward side of the building was consistently lower than on the windward side. Chan and Kwok (2000) also found that the relationship between decreases in particle mass concentrations and height was exponential in a street canyon and linear for open sites. However, other studies have shown a decrease in particle mass concentrations to certain heights, with concentrations remaining somewhat constant beyond that. In particular, Chen and Mao (1998) reported that the $\mathrm{PM}_{10}$ concentrations on the seventh and fourteenth floors were comparable, after sharply decreasing from the second floor to the seventh floor. Additionally, Kalaiarasan et al. (2009) found that $\mathrm{PM}_{2.5}$ concentrations were highest around the mid-floors when compared to those measured at the upper and lower floor of high-rise buildings. Bullin et al. (1985) reported a vertical TSP profile was nearly flat.

In contrast to particle mass, only a handful studies have measured PN concentrations around the building envelope. Väkevä et al. (1999) monitored PN concentrations at street and rooftop levels, and showed that the concentrations at $1.5 \mathrm{~m}$ were significantly higher than those at $25 \mathrm{~m}$. Hitchins et al. (2002) also observed a decrease in PN concentrations with height when measured at the front of a high rise building $80 \mathrm{~m}$ from road, but this was the opposite when measured at the rear of this building. Longley et al. (2004) noted that total number concentrations at $17 \mathrm{~m}$ were generally half of those at $4 \mathrm{~m}$ during the day and the gradient was reduced significantly at night when measurements were conducted in an asymmetric street canyon. Similarly, Kumar et al. (2009) found that PN concentrations at street level $(0.2-2.6 \mathrm{~m}$ high) were about 6.5 times higher than those at rooftop height $(20 \mathrm{~m})$. Other research conducted by Li et al. (2007) showed that PN concentrations decreased by $72 \%$ and $85 \%$ at a height of $38 \mathrm{~m}$ compared to that at $1.5 \mathrm{~m}$ when the wind blew parallel and perpendicularly the street canyon. Väkevä et al. (1999), Li et al. (2007) and Kumar et al. (2009) also discussed the influence of the photochemical aerosol particle formation relative to local vehicle emissions on vertical profile of PN concentrations. However, not only the local emissions but also other air mass from different regions, travelling with the wind direction can influence new particle formation in urban areas
(Stanier et al., 2004; Qian et al., 2007; Hussein et al., 2008; Salma et al., 2011; Cheung et al., 2011).

In addition to research surrounding building envelopes, some studies have quantified the vertical profiles of particle concentrations in urban areas. Imhof et al. (2005) has shown that PN concentrations $60 \mathrm{~m}$ downwind of a highway decreased when measured at heights of $5-30 \mathrm{~m}$. Zhu and Hinds (2005) quantified the vertical particle concentrations measured $50 \mathrm{~m}$ downwind of an elevated highway and reported that the PN concentrations increased within the first $5 \mathrm{~m}$ from the ground, then decreased at higher levels. He and Dhaniyala (2012) measured vertical profiles of PN concentrations at heights between 0.55 to $10 \mathrm{~m}$ at distances 15,50 , and $100 \mathrm{~m}$ from a highway. Their results have shown that vertical profiles of particle concentrations vary with wind speed, direction and distance from the highway.

A relationship between PN and particle mass concentrations has also been reported for urban background sites, as well as in street canyons. For example, Harrison et al. (1999) found a significant linear correlation between $\mathrm{PN}$ and $\mathrm{PM}_{10}$ concentrations at an urban background location $\left(R^{2}=0.44\right)$. Similarly, Longley et al. (2003) determined that the linear correlation $\left(R^{2}\right)$ between ultrafine $\mathrm{PN}$ and $\mathrm{PM}_{2.5}$ concentrations in a street canyon was 0.51 . However, there may be a difference in correlations between particle number size distribution (PNSD) and particle mass concentration around a building envelope due to the influence of different factors, such as emission sources, building height, and especially, the difference in particle size ranges.

Due to the inconsistent findings of previous studies, there is a lack of clear knowledge regarding PNSD, the factors affecting it, and its relationship with particle mass. The characteristics, variability and role of particle vertical profiles in both indoor and outdoor human exposure in and around urban buildings remains poorly understood. To contribute towards addressing these knowledge gaps and inform the limited experimental evidence base currently underlying numerous modelling studies, we aimed to: (1) assess the variation of PNSD, PN and $\mathrm{PM}_{2.5}$ concentrations by simultaneous measurements at the rooftop and street levels of three urban office buildings; (2) quantify vertical profiles of PNSD and $\mathrm{PM}_{2.5}$ concentration and analyse the influence of vehicle emissions and nucleation events on these vertical profiles; (3) quantify and interpret differences between PNSD and $\mathrm{PM}_{2.5}$ concentration at different levels; and (4) place the results in the context of broader literature and seek to identify if location-independent trends exist for vertical profiles of $\mathrm{PN}$ and $\mathrm{PM}_{2.5}$. 


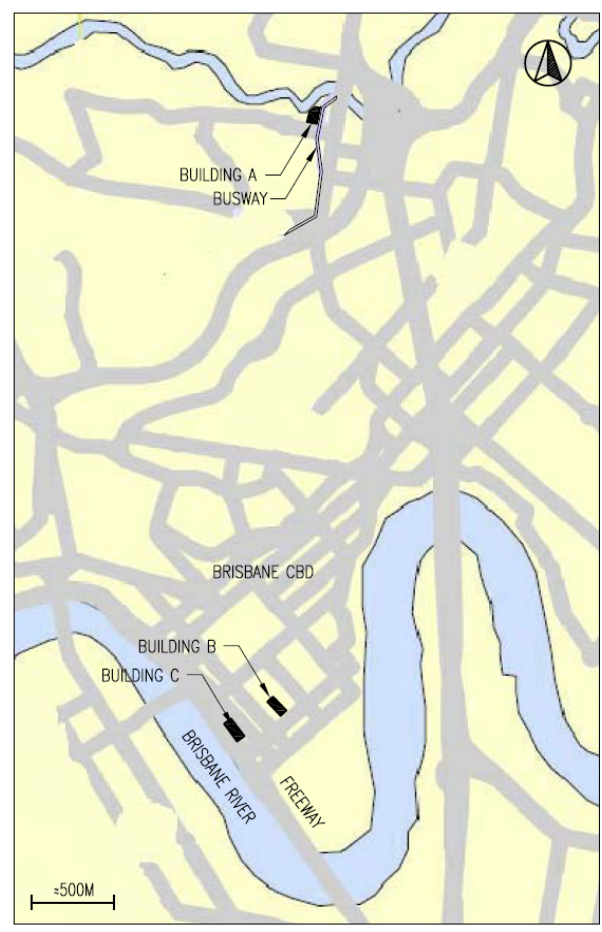

Fig. 1. Locations of Buildings A, B, and C in Brisbane.

\section{Experimental methods}

\subsection{Setting}

Our research was conducted in the subtropical city of Brisbane, which is the capital city of Queensland, Australia. Detailed information on the topography and meteorology of this region is described in Cheung et al. (2011). The major air pollution sources found in the Central Business District (CBD) are inner-city traffic emissions, and aircraft, ship and industrial emissions transported from the lower reaches of the River, located approximately $15-18 \mathrm{~km} \mathrm{NE}$ of the CBD.

We selected three urban office buildings, located close to busy roads with different terrains. Building $\mathrm{A}$ is $\sim 17 \mathrm{~m} \mathrm{high,}$ located on relatively flat ground with unrestricted access and $\sim 7 \mathrm{~m}$ from a busway, which is a bus-only roadway with a daily traffic volume of about 900 buses. Building B is $\sim 77 \mathrm{~m}$ high, located in the centre of the CBD and surrounded by other high rise buildings and busy city roads with a daily traffic volume of about 11000 vehicles. Building $\mathrm{C}$ is $\sim 25 \mathrm{~m}$ high, located $\sim 7 \mathrm{~m}$ from a freeway with a daily traffic volume of about 110000 vehicles. There are some high rise buildings to the rear of this building. The locations of Buildings A, B and $\mathrm{C}$ are shown in Fig. 1.

\subsection{Instrumentation}

Two TSI 3934 Scanning Mobility Particle Sizers (SMPSs) were used for measuring PNSD in the range $8.5-400 \mathrm{~nm}$.
Each SMPS is comprised of a TSI 3071 Electrostatic Classifier (EC) that classifies particles according to their electrical mobility, and a TSI 3010 Condensation Particle Counter (CPC). The duration of each scan was $180 \mathrm{~s}$. The PN concentrations in the range 6-3000 nm were measured using two TSI 3781 CPCs at an averaging interval of $10 \mathrm{~s}$.

Two TSI 8520 DustTrak aerosol monitors, each with a $2.5 \mu \mathrm{m}$ inlet were used to measure $\mathrm{PM}_{2.5}$ concentrations at an averaging interval of $30 \mathrm{~s}$. It should be noted that the DustTrak operates based on a light scattering technique where the amount of scattered light is proportional to the volume concentration of the aerosol. The DustTraks used to measure $\mathrm{PM}_{2.5}$ concentrations in this study were not calibrated against gravimetric readings, however this was not necessary since it was the relative values rather absolute values that were the subject of our analyses.

\subsection{Sampling sites and measurement procedures}

Two sets of instruments were used to measure PNSD, PN and $\mathrm{PM}_{2.5}$ concentrations. One measured continuously at the highest level (usually on the rooftop), which was designated as the reference site for each building. The second set measured simultaneously at one of the lower levels. The air sampled from outdoors (i.e. outside the plant room) was delivered to the instruments via a $1 \mathrm{~m}$ long conductive tubing, with an inner diameter of $6 \mathrm{~mm}$. The locations of all outdoor air sampling points were carefully considered to avoid the influence of nearby exhaust air from the HVAC system, if any. A flow splitter was used in cases where several instruments sampled air from the same location. Measurements were performed continuously for at least $24 \mathrm{~h}$ and under different wind conditions at each of the lower level sites. The measurement campaign at each building ranged from two to three weeks. The specific measurement procedures for each of the three buildings are described below.

\subsubsection{Building A}

One set of instruments continuously measured at the reference site located on the top level (level 3) $14.5 \mathrm{~m}$ above the ground, $8.5 \mathrm{~m}$ above and $7 \mathrm{~m}$ away from the busway. The second set was rotated between the ground floor, level 1 and level 2 at the front of the building (facing the busway), at heights of $\sim 1.5,6.5$ and $10.5 \mathrm{~m}$ above ground, respectively (see Fig. 2). The measurements were performed from 22 July to 16 August 2009, during the Australian winter period.

\subsubsection{Building B}

The reference site was located on the rooftop, about $78.5 \mathrm{~m}$ above road level, and one set of instruments sampled continuously at this location. The second set simultaneously sampled at $1.5 \mathrm{~m}$ above and $\sim 5 \mathrm{~m}$ from the roadway, as shown in Fig. 3, since there were no other access points available at other levels due to the tight glass wall structure of the 

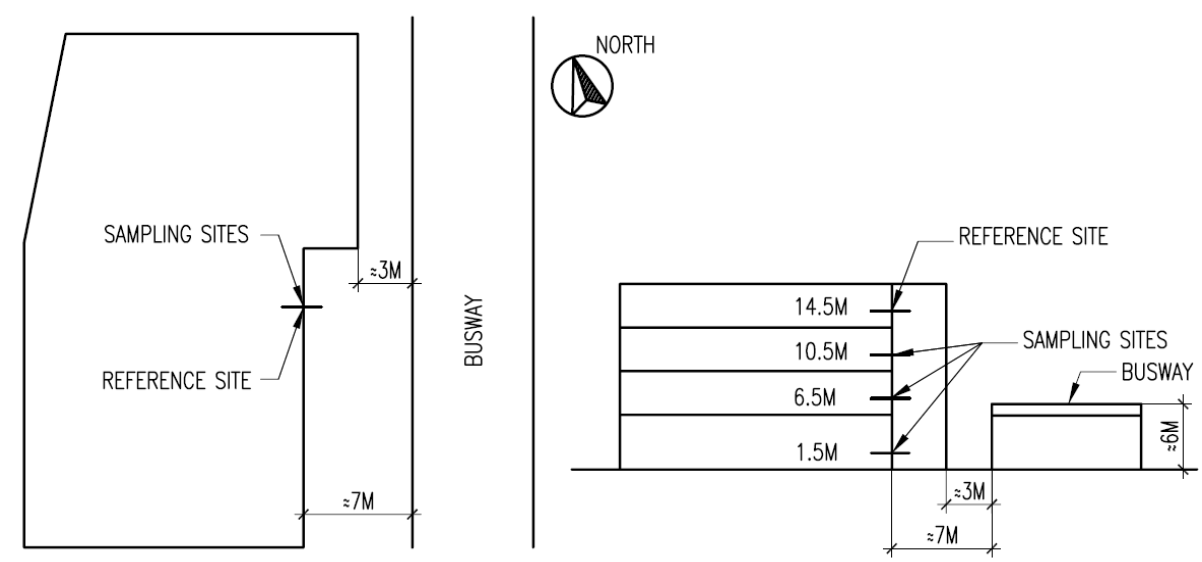

Fig. 2. Schematic diagram of Building A and the locations of the sampling points.
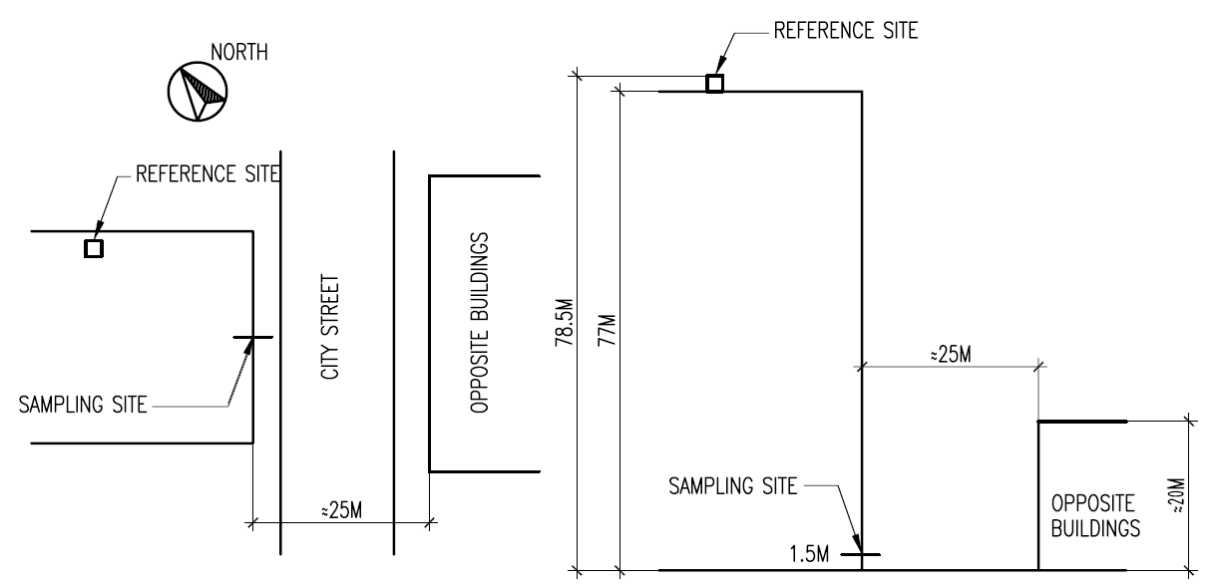

Fig. 3. Schematic diagram of Building B and the location of the sampling points.

building. Measurements were performed from 14 to 30 January 2010, during the Australian summer period.

\subsubsection{Building $\mathrm{C}$}

One set of instruments sampled continuously at the reference site, which was located $21.5 \mathrm{~m}$ above the ground, and $13.5 \mathrm{~m}$ above and $7 \mathrm{~m}$ away from the freeway. The second set was moved between sites located at heights of $\sim 1.5 \mathrm{~m}, 5.5 \mathrm{~m}$, $9.5 \mathrm{~m}$ and $21.5 \mathrm{~m}$ (levels 1, 2, 3 and 6, respectively) on the opposite side of the building to the reference site (the rear of the building). The sampling sites and building layout are shown in Fig. 4. Measurements were performed from 24 June to 16 July 2010, during the Australian winter period.

\subsection{Meteorological data}

Meteorological parameters, including wind speed, wind direction, temperature and relative humidity corresponding to each measurement campaign were obtained from the Queensland Bureau of Meteorology weather station located in Brisbane CBD between 1 to $5 \mathrm{~km}$ east to south east of the measurement sites. Global solar radiation was collected at the Queensland Department of Environment and Resource Management site, about 10 to $14 \mathrm{~km}$ south of the measurement sites. A summary of the meteorological data is provided in Table 1.

\subsection{Identification of nucleation event}

Morawska et al. (2008) has shown that motor vehicle emissions are the major source of air pollution in urban environments. Particles from vehicle emissions are classified as either primary or secondary. The primary particles are generated directly from engines and range in size from 30$500 \mathrm{~nm}$. The secondary particles are formed via nucleation in the atmosphere after emissions from the tailpipe and are generally below $30 \mathrm{~nm}$.

In order to identify nucleation events, contour plots of data based on a 24-h period, from 00:00-24:00, were visually analysed. Criteria proposed by Dal Maso et al. (2005) and Hussein et al. (2008) were then applied to identify nucleation events. These criteria are: (i) a distinctly new mode of 


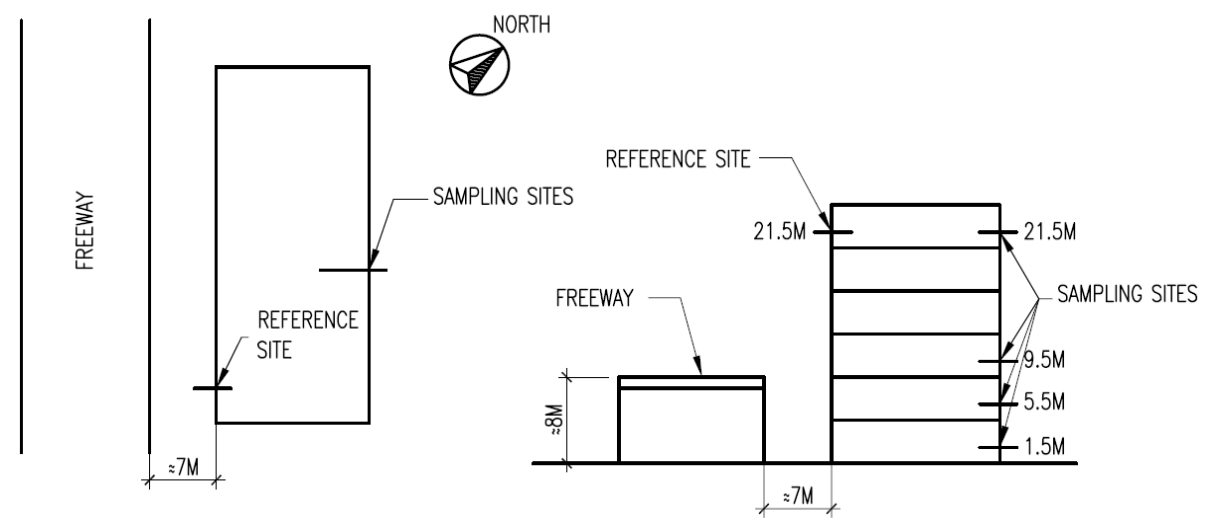

Fig. 4. Schematic diagram of Building $C$ and the locations of the sampling points.

Table 1. Average meteorological conditions ( \pm standard deviation).

\begin{tabular}{llll}
\hline Meteorological parameters & $\begin{array}{l}\text { Building A } \\
\text { 22 July-16 August 2009 }\end{array}$ & $\begin{array}{l}\text { Building B } \\
\text { 14-30 January 2010 }\end{array}$ & $\begin{array}{l}\text { Building C } \\
\text { 24 June-16 July 2010 }\end{array}$ \\
\hline Wind speed $\left(\mathrm{m} \mathrm{s}^{-1}\right)$ & $1.7 \pm 1.2$ & $2.4 \pm 1.3$ & $1.3 \pm 1.1$ \\
Solar radiation intensity $\left(\mathrm{W} \mathrm{m}^{-2}\right)$ & $204 \pm 209$ & $343 \pm 429$ & $123 \pm 203$ \\
Temperature $\left({ }^{\circ} \mathrm{C}\right)$ & $15.7 \pm 4.4$ & $26.6 \pm 3.2$ & $15.2 \pm 3.4$ \\
Relative humidity $(\%)$ & $68.9 \pm 18.8$ & $63.7 \pm 13.8$ & $69.6 \pm 13.1$ \\
\hline
\end{tabular}

particles must appear in the size distribution; (ii) the mode starts in size range of $<30 \mathrm{~nm}$; (iii) the mode prevails over a time period of hours; and (iv) the new mode shows signs of growth. In urban environments, nucleation events have been observed both with and without particle growth (Cheung et al., 2011; Gao et al., 2009; Park et al., 2008). Therefore, an event where the nucleation mode particle number concentrations increased during the day, but the particles did not grow larger during the event period, as indicated by a near constant Geometric Mean Diameter (GMD) value, was also considered as a nucleation event. Atmospheric conditions during the events were also recorded to identify the preconditions for nucleation process.

\subsection{Data analyses}

In order to compare PN concentrations in different size ranges at street and rooftop levels, $\mathrm{PN}$ concentrations were classified into the following size ranges: $8.5-30 \mathrm{~nm}, 30$ $50 \mathrm{~nm}, 50-100 \mathrm{~nm}, 30-100 \mathrm{~nm}, 100-300 \mathrm{~nm}$ and $30-300 \mathrm{~nm}$. The number of particles within each range was referred to as $N_{<30}, N_{30-50}, N_{50-100}, N_{30-100}, N_{100-300}$ and $N_{30-300}$, respectively.

Vertical profiles of PNSD and $\mathrm{PM}_{2.5}$ concentrations for each building were determined by normalising measured concentrations to the reference site. These were calculated as the ratio of concentrations measured at the different levels to the corresponding concentration at the reference site. Following this, the mean ratios of normalised concentrations were shifted so that the lowest height of each building was
1.0. This allowed trends of increasing or decreasing concentrations to be interpreted as values larger or smaller than one.

Statistical analyses included the Student's t-test to assess differences in mean particle concentrations between different heights and time periods. Paired PNSD and $\mathrm{PM}_{2.5}$ concentrations corresponding to different heights at each building were analysed using the linear correlations. The $5 \%$ level was taken to indicate statistical significance in all cases.

\section{Results and discussion}

\subsection{Variation of PNSD at rooftop and street levels}

Whilst "rooftop level" refers to the reference site at each building, the "street level" varied for each building depending on the height of the busy road close by. For example, the height of level 1 at Building $\mathrm{A}$ is approximately the same height as the nearby busway, and therefore, the measurements conducted at level 1 are considered to be "street level" measurements. Similarly, the ground floor of Building B (close to city street level) and level 3 of Building C (close to the freeway) are also referred to as "street level".

To interpret the daily pattern of PNSD at rooftop and street levels of each building, PNSD spectra and average daily PN concentrations for $N_{<30}, N_{30-50}, N_{50-100}$, and $N_{100-300}$ were plotted against time of the day for Buildings A, B and $\mathrm{C}$ (see Figs. 5, S1 and $\mathrm{S} 2$, respectively). In general, PNSD trends at rooftop and street levels were similar at each building. 


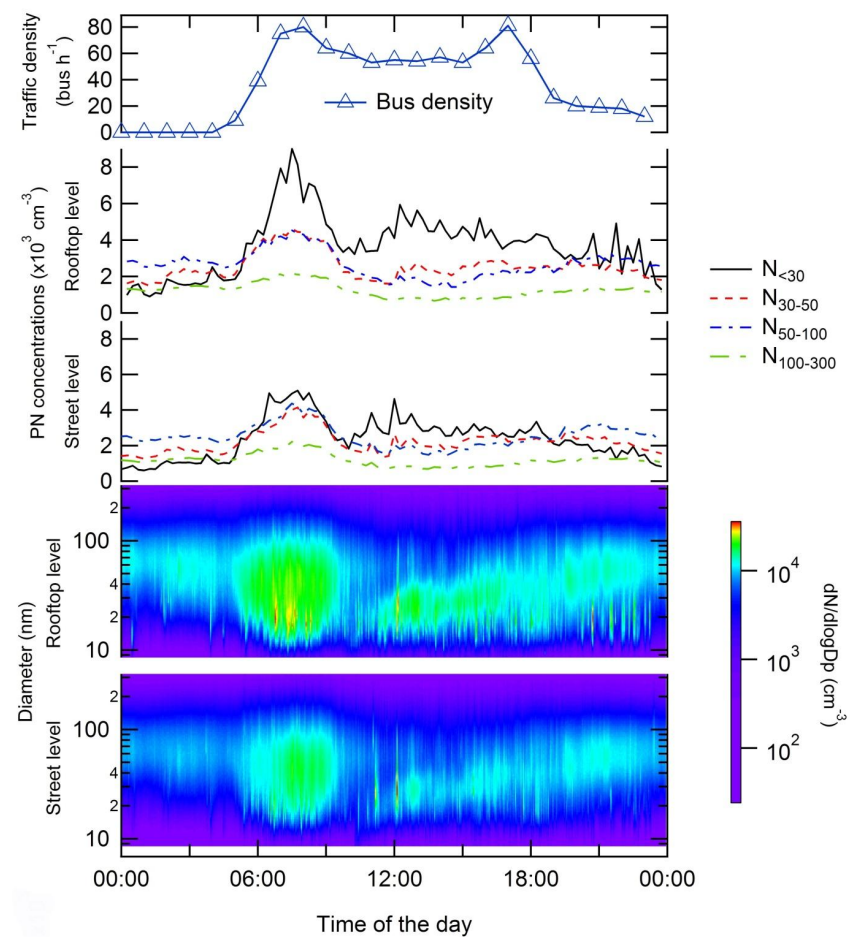

Fig. 5. Daily variation in PNSD and PN size fraction concentrations at Building A.

At the rooftop and street levels of Building A, PN size fraction concentrations increased in the early morning and late afternoon. However, the concentrations in the morning were higher than those in the afternoon. During the middle of the day (noon) and early afternoon, $N_{<30}$ repeatedly increased while other particle size concentrations remained constant or decreased. At Building B, $N_{<30}$ increased significantly during the early afternoon, while other particle size range concentrations decreased at both the rooftop and street levels. Similar to Building A, all particle size concentrations at Building $\mathrm{C}$ increased in the early morning and late afternoon, while only $N_{<30}$ increased again around noon.

Daily mean variations of PN size fraction concentrations increased in the early morning and late afternoon at Buildings A and C. Traffic flows on the streets close to the sampling sites also showed corresponding peaks during these times, which indicate the influence of vehicle emissions on increased particle concentrations during the rush hours. In contrast, $N_{<30}$ concentration increased at noon, while other particle size ranges remained constant or decreased at both the rooftop and street levels of all three buildings. In addition, the traffic flow rates decreased around midday. This could suggest the occurrence of new particle formation during this period. A detailed analysis and discussion of the influence of vehicle emissions and new particle formation on particle concentrations is provided in the following section.

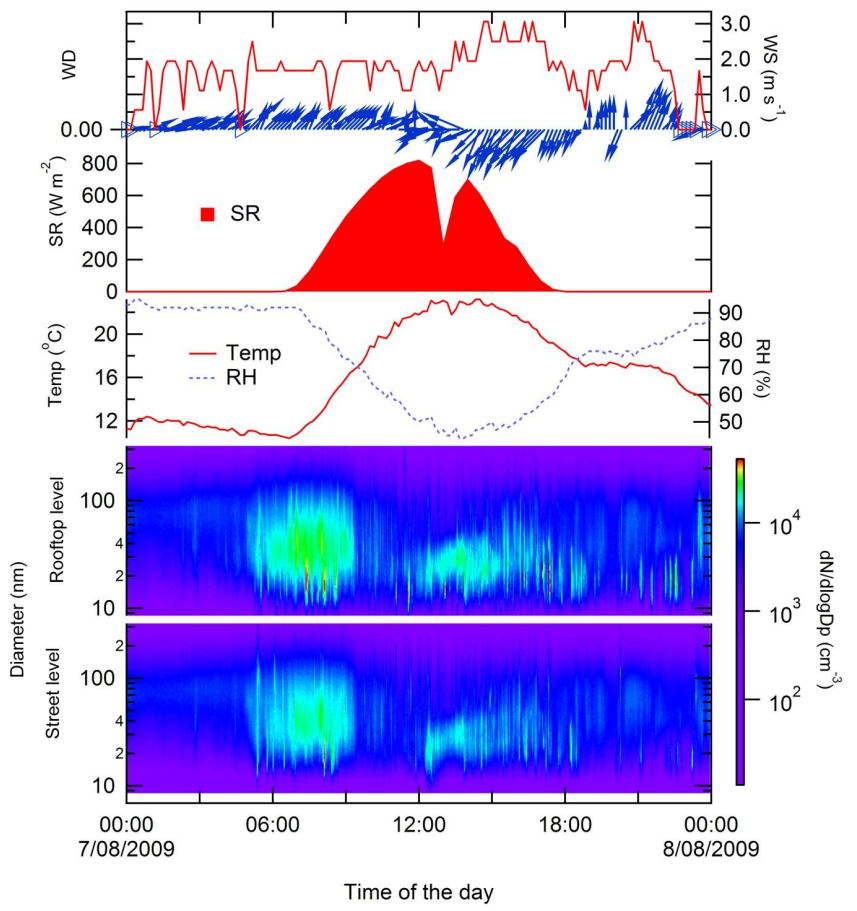

Fig. 6. PNSD spectra at Building A on a week day characterised by the non- or unclear nucleation events.

\subsection{Influence of vehicle emissions and new particle formation on PNSD and PM$_{2.5}$ concentrations at rooftop and street levels}

\subsubsection{Influence of vehicle emissions on $P N$ and $\mathbf{P M}_{2.5}$ concentrations at rooftop and street levels}

The days that did not meet at least one of the criteria for the nucleation event definition were defined as a non- or unclear nucleation event day. Based on this, there were 19, 8 , and 20 days that were classified as non- or unclear nucleation event at Building A, B, and C, respectively. Weekdays characterised by non- or unclear nucleation events were selected to assess the influence of vehicle emissions on the PN and $\mathrm{PM}_{2.5}$ concentrations at the rooftop and street levels of each building. Examples of PNSD spectra, $\mathrm{PN}$ and $\mathrm{PM}_{2.5}$ time series plots at the rooftop and street levels of Buildings $\mathrm{A}, \mathrm{B}$ and $\mathrm{C}$, as well as their ratios are presented in Figs. 6, 7, S3, S4, S5 and S6, respectively. Statistical results are given in Table 2.

From Fig. 7 it can be seen that both $\mathrm{PN}$ and $\mathrm{PM}_{2.5}$ concentrations peaked at the rooftop and street levels of Building A during the early morning on 7 August 2009. However, $\mathrm{PN}$ concentration at the rooftop level was significantly higher than at street level, while the opposite was the case for $\mathrm{PM}_{2.5}$. The bus ramp located close to Building A may explain the higher $\mathrm{PN}$ and $\mathrm{PM}_{2.5}$ concentrations in the morning rush hours compared to those in the afternoon rush hours. About $75 \%$ (157/209) of buses during the morning rush hour have 


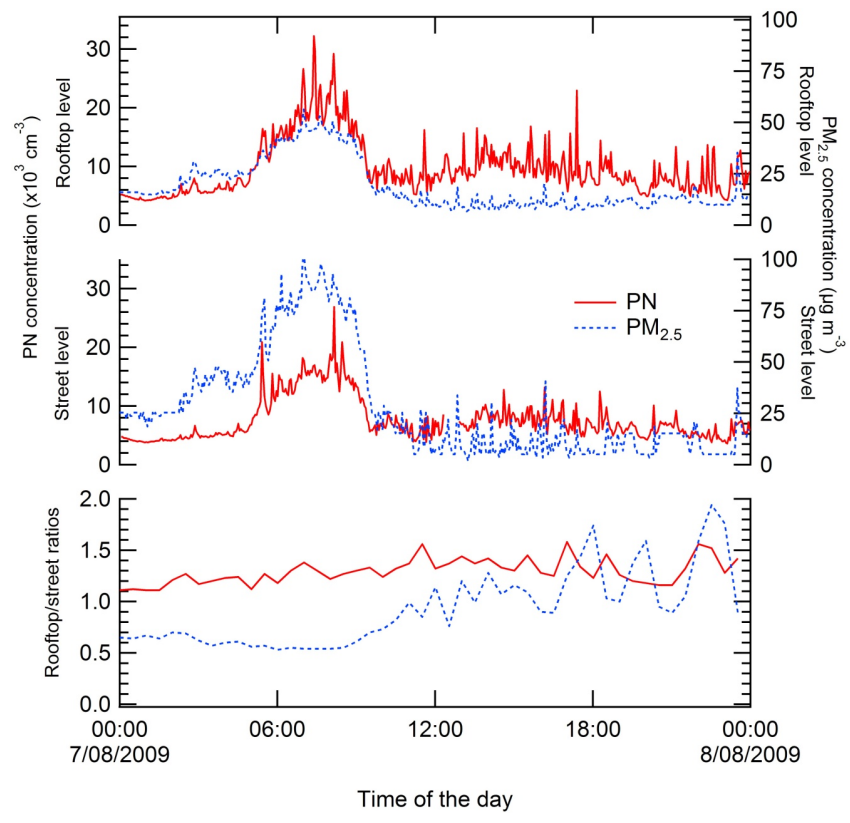

Fig. 7. Average particle concentrations and their rooftop to street level ratios at Building A on a week day characterised by the nonor unclear nucleation events.

to ascend an uphill ramp, and these would have greater emissions than those during the afternoon rush hours that predominantly travel downhill.

PN concentration at the rooftop and street levels of Building B on 18 January 2010, fluctuated according to the wind conditions during the day. However, both $\mathrm{PN}$ and $\mathrm{PM}_{2.5}$ concentrations at street level were significantly higher than those at the rooftop level during the morning and afternoon rush hours when the wind blew from SW and NE directions. This can be explained by the one-way city street immediately adjacent to the lower sampling site at Building B, which had a traffic flow from the SW to the NE and therefore both SW and NE winds blew parallel the street. Given that the NE wind blew against the traffic flow, it was classified as up-canyon wind, while the SW wind was classified as down-canyon wind. Both PN and $\mathrm{PM}_{2.5}$ concentrations at the rooftop and street levels were significantly higher during up-canyon wind (in the afternoon) compared to down-canyon wind (in the morning) (refer to Table 2 for comparative results) and ratios between the street and rooftop levels for both PN and $\mathrm{PM}_{2.5}$ concentrations were also significantly higher during the up-canyon wind compared to the down-canyon wind.

At Building $\mathrm{C}, \mathrm{PN}$ and $\mathrm{PM}_{2.5}$ concentrations at the roof top level were significantly higher than those at street level during the morning rush hours on 6 July 2010. Low dispersion due to low wind speed $\left(v=0.31 \pm 0.29 \mathrm{~m} \mathrm{~s}^{-1}\right)$ during this time might explain why the particle concentrations at the rooftop sampling point, which was closer to the freeway, were higher than those at the opposite sampling point at street level. During the afternoon, a WNW wind blew al- most parallel to the freeway and the building, resulting in a better dispersion of pollutants on both sides of the building and also being the likely explanation why the $\mathrm{PN}$ and $\mathrm{PM}_{2.5}$ concentrations were not significantly different at the rooftop and street levels (p-values of 0.06 and 0.45 , respectively).

In summary, time series of $\mathrm{PN}$ and $\mathrm{PM}_{2.5}$ concentrations and their ratios between the rooftop and street levels showed clear diurnal variation. As expected, vehicle emissions strongly influenced both $\mathrm{PN}$ and $\mathrm{PM}_{2.5}$ concentrations at both levels, especially during the rush hours at all three buildings. Similarly, building topography, distance to the emission sources, and wind speed and direction also had an observed effect on particle concentrations at the 3 buildings.

\subsubsection{Influence of new particle formation on PNSD and $\mathbf{P M}_{2.5}$ concentrations at rooftop and street levels}

Based on the inclusion criteria for nucleation identification, we observed 7 events during a 3 weeks measurement campaign at Building A, 9 events during a 2 weeks measurement campaign at Building B and 3 events during a 3 weeks measurement campaign at Building $\mathrm{C}$. The frequency of nucleation events at Building $\mathrm{B}$ (measured during summer) was clearly higher than those at Buildings $\mathrm{A}$ and $\mathrm{C}$ (measured during winter), which is in agreement with the findings of Qian et al. (2007) and Mejía and Morawska (2009). A summary of the conditions observed during the nucleation events is provided in the Supplement Table S1.

Representative nucleation events were selected to analyse the influence of new particle formation on PNSD at the rooftop and street levels of each building, to assess their likely sources and impact on vertical profiles. PNSD spectra, time series' of $N_{<30}, N_{30-100}$ and $\mathrm{PM}_{2.5}$ concentrations, as well as ratios of $\mathrm{PN}$ and $\mathrm{PM}_{2.5}$ concentrations at the rooftop and street levels of Buildings A, B and C are presented in Figs. 8, 9, S7, S8, S9 and S10, respectively. The results of statistical tests are presented in Table 3 .

$N_{<30} / N_{30-300}$, which is the ratio between nucleation mode and accumulation mode PN concentration, was used by Kumar et al. (2009) to evaluate the rate of production of new nucleation mode particles. When analysed together with $N_{<30}$, which indicates nucleation mode PN concentration, it is possible to assess the strength of new particle formation at the different levels of each building. From Table 3, it can be seen that both $N_{<30}$ and $N_{<30} / N_{30-300}$ were significantly higher at the rooftop level compared to street level at each building, and they were also clearly higher at Building B than at Buildings $\mathrm{A}$ and $\mathrm{C}$. Meanwhile the rooftop $\mathrm{PM}_{2.5}$ concentration was significantly lower than the street level $\mathrm{PM}_{2.5}$ at all three buildings.

Based on the higher values of $N_{<30}$ and $N_{<30} / N_{30-300}$ at the rooftop level of each building, we inferred that the production of new nucleation mode particles was stronger at the rooftop level than the street level at all three buildings. Väkevä et al. (1999) reported two important factors that can 
Table 2. Average particle concentrations during rush-hours on non- or unclear nucleation days.

\begin{tabular}{|c|c|c|c|c|c|c|c|}
\hline \multirow[t]{2}{*}{ Site } & \multirow[t]{2}{*}{ Level } & \multicolumn{3}{|c|}{$\mathrm{PN}\left(\times 10^{3} \mathrm{~cm}^{-3}\right)($ Mean $\pm 95 \% \mathrm{CI})$} & \multicolumn{3}{|c|}{$\mathrm{PM}_{2.5}\left(\mu \mathrm{g} \mathrm{m}^{-3}\right)($ Mean $\pm 95 \% \mathrm{CI})$} \\
\hline & & Morning & Afternoon & $p$ & Morning & Afternoon & $p$ \\
\hline \multirow[t]{3}{*}{ Building A } & Rooftop & $18.73 \pm 1.21$ & $9.99 \pm 0.73$ & $<0.01$ & $42.90 \pm 1.74$ & $10.10 \pm 0.62$ & $<0.01$ \\
\hline & Street & $14.51 \pm 0.85$ & $7.56 \pm 0.43$ & $<0.01$ & $78.50 \pm 3.69$ & $11.80 \pm 0.86$ & $<0.01$ \\
\hline & $p$ & $<0.01$ & $<0.01$ & & $<0.01$ & $<0.01$ & \\
\hline \multirow[t]{3}{*}{ Building B } & Rooftop & $5.01 \pm 0.37$ & $5.82 \pm 0.64$ & $<0.05$ & $8.51 \pm 0.48$ & $9.59 \pm 0.27$ & $<0.01$ \\
\hline & Street & $6.04 \pm 0.65$ & $7.21 \pm 0.69$ & $<0.05$ & $19.64 \pm 1.14$ & $22.02 \pm 1.22$ & $<0.01$ \\
\hline & $p$ & $<0.01$ & $<0.01$ & & $<0.01$ & $<0.01$ & \\
\hline \multirow[t]{3}{*}{ Building C } & Rooftop & $18.64 \pm 1.21$ & $8.56 \pm 0.65$ & $<0.01$ & $19.00 \pm 0.51$ & $8.00 \pm 0.67$ & $<0.01$ \\
\hline & Street & $12.48 \pm 1.70$ & $8.12 \pm 0.52$ & $<0.01$ & $17.70 \pm 0.79$ & $8.20 \pm 0.56$ & $<0.01$ \\
\hline & $p$ & $<0.01$ & 0.06 & & $<0.05$ & 0.45 & \\
\hline
\end{tabular}

Table 3. Average particle concentrations during nucleation events.

\begin{tabular}{lllll}
\hline Site & Level & $\begin{array}{l}N_{<30}\left(\times 10^{3} \mathrm{~cm}^{-3}\right) \\
(\text { Mean } \pm 95 \% \mathrm{CI})\end{array}$ & $\begin{array}{l}N_{<30} / N_{30-300} \\
(\mathrm{Mean} \pm 95 \% \mathrm{CI})\end{array}$ & $\begin{array}{l}\mathrm{PM}_{2.5}\left(\mu \mathrm{g} \mathrm{m}^{-3}\right) \\
(\mathrm{Mean} \pm 95 \% \mathrm{CI})\end{array}$ \\
\hline Building A & Rooftop & $8.16 \pm 1.02$ & $1.76 \pm 0.33$ & $11.34 \pm 1.11$ \\
& Street & $4.57 \pm 0.28$ & $1.01 \pm 0.08$ & $19.74 \pm 3.50$ \\
& $p$ & $<0.01$ & $<0.01$ & $<0.01$ \\
\hline Building B & Rooftop & $16.90 \pm 1.49$ & $4.54 \pm 0.52$ & $4.0 \pm 0.08$ \\
& Street & $15.65 \pm 1.47$ & $3.92 \pm 0.34$ & $7.5 \pm 0.65$ \\
& $p$ & $<0.05$ & $<0.01$ & $<0.01$ \\
\hline Building C & Rooftop & $5.34 \pm 0.45$ & $2.23 \pm 0.32$ & $1.67 \pm 0.18$ \\
& Street & $3.31 \pm 0.27$ & $1.91 \pm 0.24$ & $2.01 \pm 0.14$ \\
& $p$ & $<0.01$ & $<0.01$ & $<0.01$ \\
\hline
\end{tabular}

favour a much greater production of particles by local vehicle emissions: (i) a higher concentration of condensable gases, and (ii) a smaller concentration of pre-existing particles. Additionally, both O'Dowd et al. (1999) and Boy and Kulmala (2002) identified the important role of solar radiation on new particle formation. The roles of these factors in initiating the events we observed are discussed below.

Wind direction during the nucleation event at Building A on 3 August 2009, was WNW. In this case, both sampling sites and the busway were on the downwind side of the building. Leuzzi and Monti (1998) modelled the dispersion of a tracer gas emitted from a line source located downwind of a building and reported that high pollutant concentrations occurred at locations corresponding to the vortex on the leeward side of the building. At about $40 \mathrm{~m}$ wide and $17 \mathrm{~m}$ high, Building A can be considered a wide and low building and therefore the vortex, which entrains the smaller particles or condensable gases emitted from vehicles, probably formed at a level higher than the street level, while the larger or preexisting particles (mainly attributed to $\mathrm{PM}_{2.5}$ ) remained suspended and stagnated at the lower levels. Therefore, it appears that the stronger nucleation observed at the rooftop compared to the street level was due to higher condensable gas and lower pre-existing particle concentrations.

Leuzzi and Monti (1998) also modelled an upwind line source and reported that low concentrations occurred on the leeward side of the building, with only a small amount of pollutants able to penetrate into the region. During the nucleation event at Building C on 8 July 2010, a SSW wind blew perpendicular to the building from direction of the freeway. Therefore, the rooftop sampling site was upwind and received pollutants directly from the freeway emission sources, while the street level sampling site was located in the lee of the building. This suggests that there were lower concentrations of condensable gases at the street level compared to the rooftop level of Building $\mathrm{C}$ and that the higher $\mathrm{PM}_{2.5}$ concentrations measured at street level might be due to the stagnation of larger, pre-existing particles on the leeward side of the building.

Based on $N_{<30}$ and $N_{<30} / N_{30-300}$ at rooftop and street levels, we also concluded that the intensity of new particle formation at Building B on 16 January 2010, was clearly stronger than that at Buildings $\mathrm{A}$ and $\mathrm{C}$, although the mean solar radiation intensity $\left(\mathrm{W} \mathrm{m}^{-2}\right)($ Mean $\pm 95 \% \mathrm{CI})$ during the nucleation event at Building $\mathrm{B}$ was not significantly 


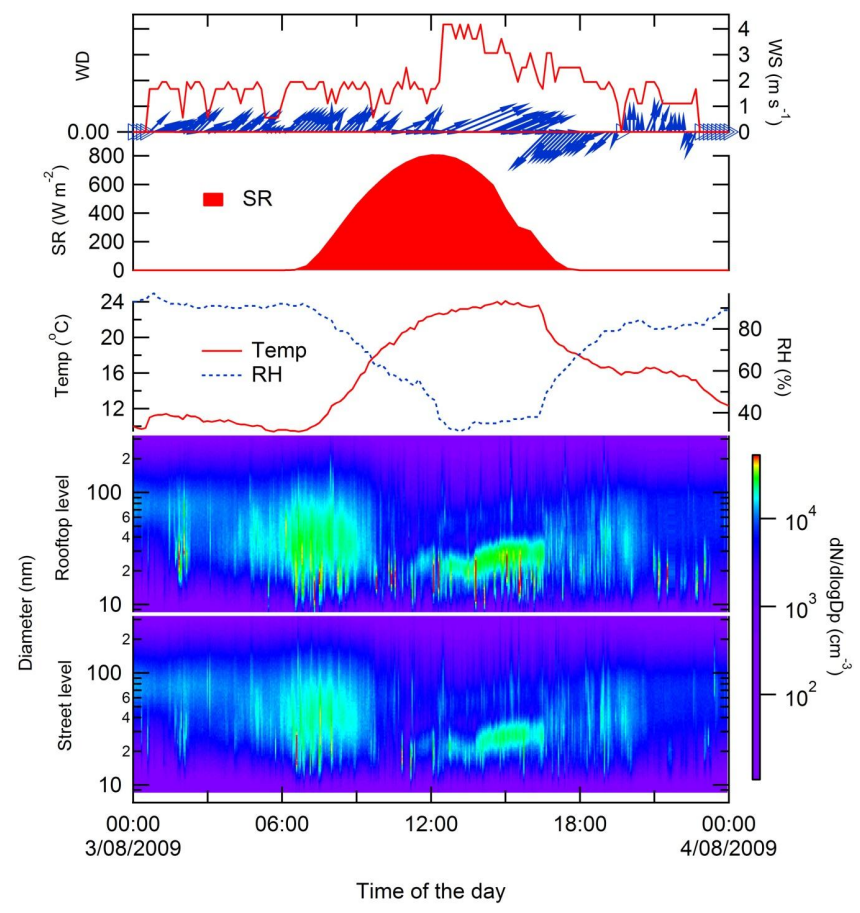

Fig. 8. PNSD spectra at Building A on a nucleation event day.

different compared to Building A $(664.3 \pm 20.7$ vs. $689.4 \pm$ 22.4, $p=0.36$ ). At the same time, ratios between rooftop and street level values for $N_{<30}$ and $N_{<30} / N_{30-300}$ were significantly lower at Building $\mathrm{B}$ compared to those at Building $\mathrm{A}(1.15 \pm 0.09$ vs. $1.88 \pm 0.27, p<0.01 ; 1.20 \pm 0.14$ vs. $1.84 \pm 0.30, p<0.01$, respectively). The nucleation event observed at Building B occurred on a weekend, when vehicle density was typically low and a strong NE wind $(3.57 \pm$ $0.32 \mathrm{~m} \mathrm{~s}^{-1}$ ) was blowing. The resultant increase in $N_{<30}$ but decrease in $N_{30-100}$ suggests that the PN concentrations at the sampling site were not significantly influenced by local vehicle emissions but more likely from upwind air masses. In this case, the air mass was likely to come from an industrial zone about $15-18 \mathrm{~km} \mathrm{NE}$ of the city. Further analysis and comparison of the data measured at this building was conducted along with data collected from a Queensland Department of Environment and Resource Management station, which is about $10 \mathrm{~km} \mathrm{SW}$ of the Brisbane city and $25 \mathrm{~km} \mathrm{SW}$ of the NE Brisbane industrial zone. The results showed similar trends in PN concentrations between the two locations during the NE winds, but not for other wind directions, during the nucleation days. This implies that emissions from the NE Brisbane industrial zone are those which contribute to the PN concentrations in the Brisbane CBD and surrounding areas. Furthermore, a similar phenomenon was identified and reported by Cheung et al. (2011) in the Brisbane region. It should also be noted that newly formed particles at both the rooftop and street levels did not show signs of growth (their GMDs were almost constant during the event). This indicates

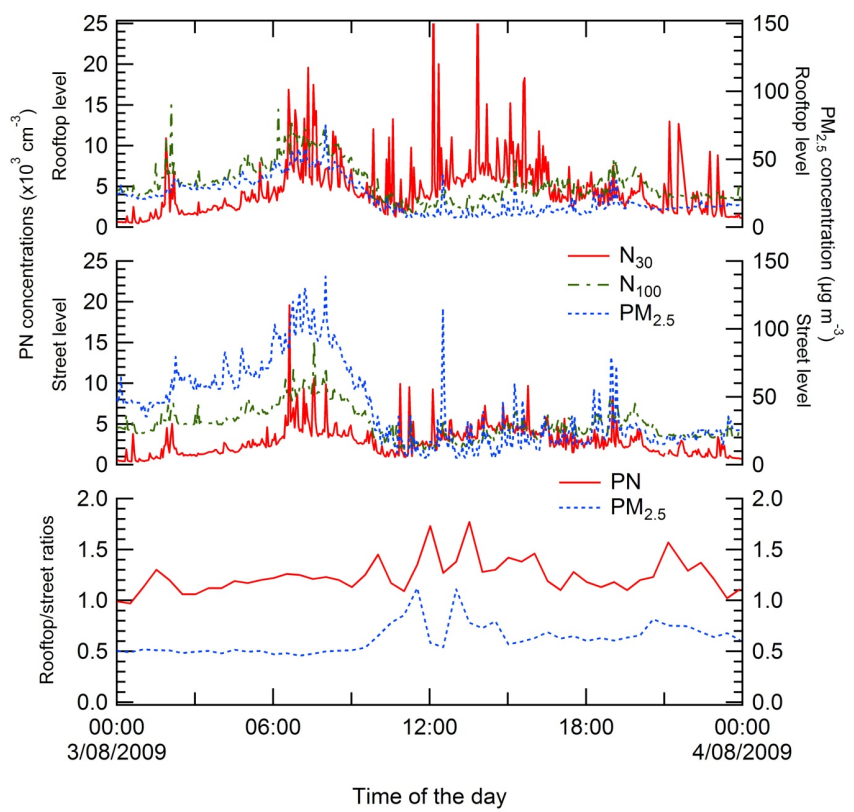

Fig. 9. Particle concentrations and their rooftop to street level ratios at Building A during a nucleation event day.

that the newly formed particles already underwent growth before reaching the monitoring sites and they were likely to be relatively homogeneous in size when reaching Building B after the distance travelled. Furthermore, the NE wind, which would have blown parallel to the street canyon, and minimal turbulence due to the low vehicle density could explain why the difference in $\mathrm{PN}$ concentrations $\left(\mathrm{cm}^{-3}\right)$ between the rooftop and street levels at Building B (16900 \pm 1490 vs. $15650 \pm 1470 ; p<0.05$ ) was significant, but not to the same extent observed at Buildings A $(8160 \pm 1020$ vs. $4570 \pm 280$; $p<0.01)$ and $C(5340 \pm 450$ vs. $3310 \pm 270 ; p<0.01)$. This new finding contradicts the results reported for Building A and locations investigated by Kumar et al. (2009), where new particle formation was mainly influenced by local vehicle emissions. This also has implications for modelling urban canyon PN concentrations for both planning and exposure assessment purposes, and indicates the value of locationspecific measurements at underpinning these.

In summary, the time series concentrations of $N_{<30}$, $N_{30-100}$ and $\mathrm{PM}_{2.5}$, as well as the time series ratios of $\mathrm{PN}$ and $\mathrm{PM}_{2.5}$ concentrations at the rooftop and street levels showed that new particle formation events influenced and contributed to increases in PN concentrations at both rooftop and street levels at all three buildings. However, the factors that contributed to the observed phenomena were different between the three buildings. At Building A and C, the new particles were mainly formed from local vehicle emissions and therefore, the formation process was expected to depend mainly on local conditions, such as high condensable gas concentrations and solar radiation intensity, together with low preexisting particle concentrations. Meanwhile at Building B, 


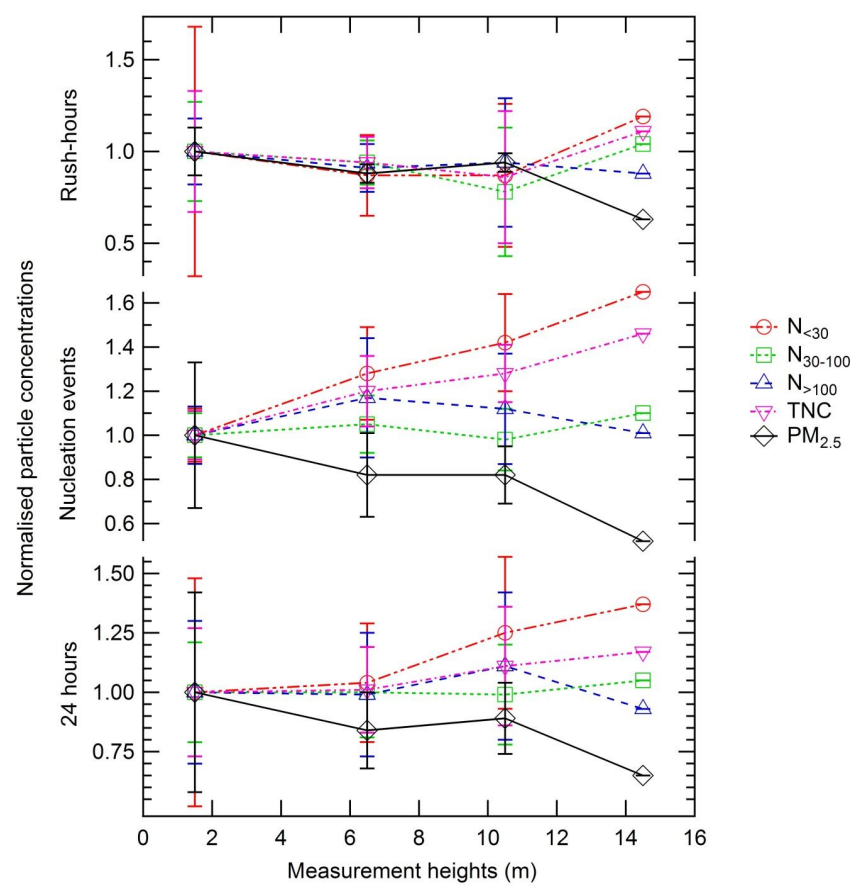

Fig. 10. Vertical profiles of PNSD and $\mathrm{PM}_{2.5}$ concentration around Building A. Error bars denote one standard deviation.

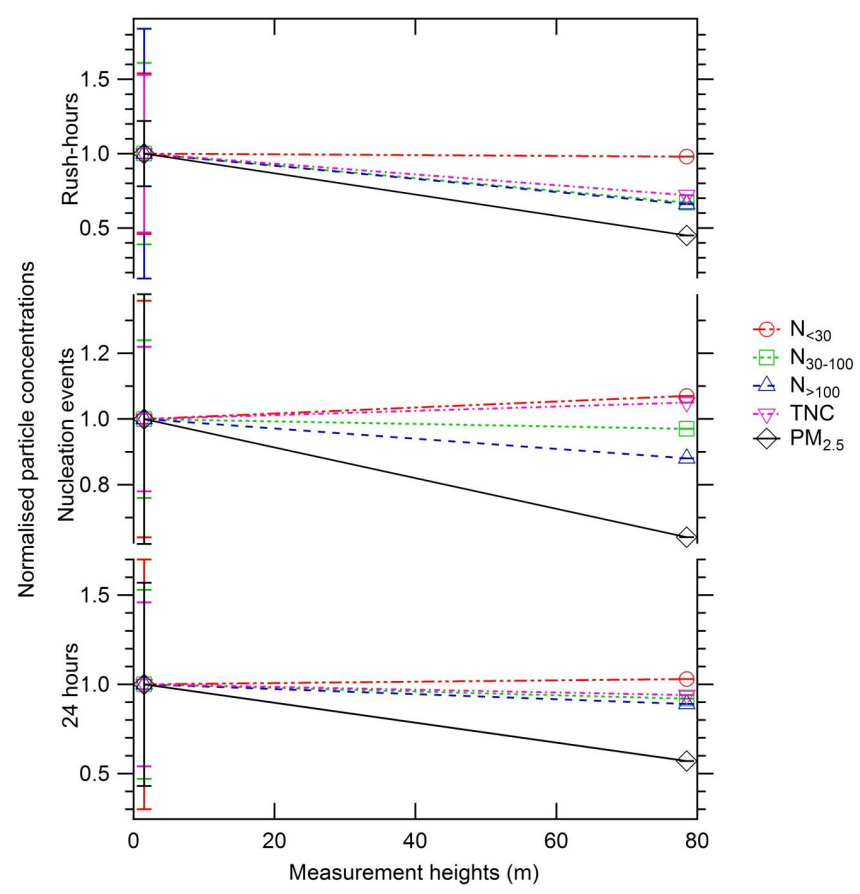

Fig. 11. Vertical profiles of PNSD and $\mathrm{PM}_{2.5}$ concentration around Building B. Error bars denote one standard deviation.

the newly formed particles were blown in from the direction of a nearby industrial zone and therefore, new particle production was not the result of local sources but was strongly influenced by wind speed, wind direction and the origin of

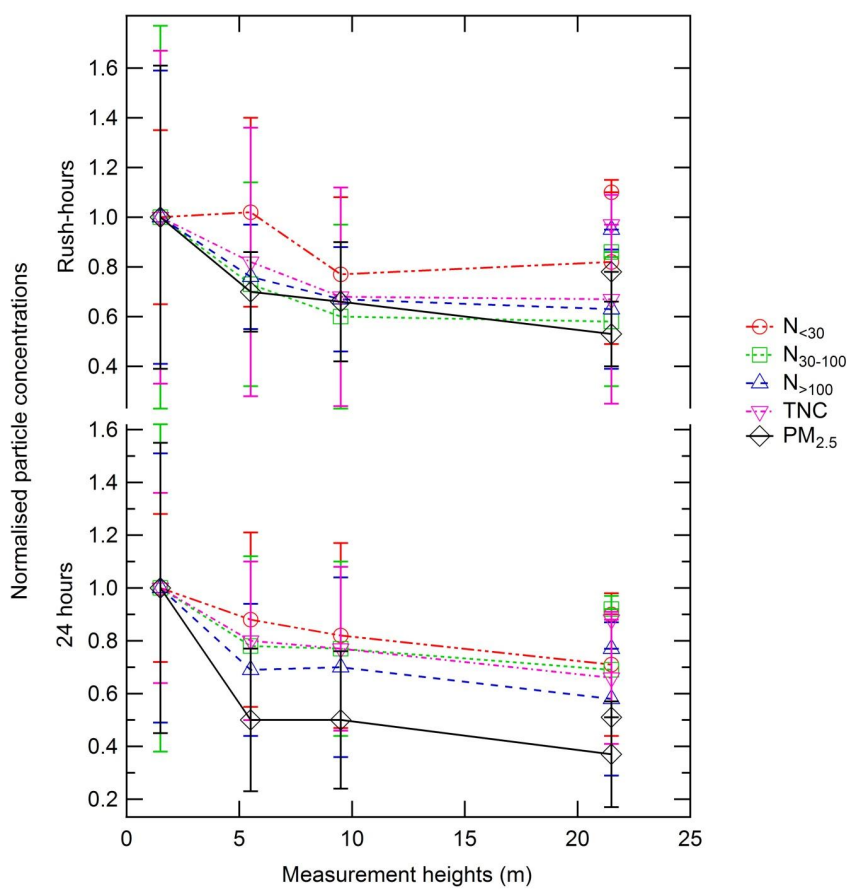

Fig. 12. Vertical profiles of PNSD and $\mathrm{PM}_{2.5}$ concentration around Building C. Error bars denote one standard deviation.

incoming air masses. Detailed consideration of the factors described above should be undertaken prior to modelling urban canyon particle concentrations and profiles, and a "onesize-fits-all" approach is likely to be unable of accounting for the specific determinants at each individual building.

Nucleation events are often studied in the context of their role as physical phenomena, and typically within the context of producing natural and anthropogenic aerosols that may affect climate change. This study has shown an underappreciated role of nucleation in producing particles that can affect large numbers of people, due to the high density and occupancy of urban office buildings and the fact that the vast majority of people's time is spent indoors.

\subsection{Vertical profiles of particle concentrations}

The average vertical profiles of the PNSD and $\mathrm{PM}_{2.5}$ for the entire day, rush-hours and during nucleation events at Buildings $\mathrm{A}, \mathrm{B}$, and $\mathrm{C}$ are presented in Figs. 10, 11 and 12, respectively. It should be noted that the data of the nucleation events at Building $\mathrm{C}$ were only collected at rooftop and street levels and therefore, constructing a vertical profile based on nucleation events at this building, was not appropriate. However, the measured results at Building $\mathrm{C}$ show that the PN concentration at rooftop levels was significantly higher than at street levels during the event, while the opposite was the case for the $\mathrm{PM}_{2.5}$ concentration.

At Building $\mathrm{A}$, the trends of total number concentration (TNC) and $N_{<30}$ were similar. Their concentrations 
during nucleation events themselves and over $24 \mathrm{~h}$ on the day of nucleation events constantly increased with height $(p<0.01)$. While during the rush-hours, they decreased between 1.5 and $10.5 \mathrm{~m}$, and then increased onward $(p<0.05)$. In contrast, the trends of $N_{30-100}$ and $N_{>100}$ fluctuated and depended on the measurement heights and times. In general, the daily $\mathrm{PM}_{2.5}$ concentrations decreased with increasing height, however they stabilised at heights between 6.5 and $10.5 \mathrm{~m}$. During rush-hours, $\mathrm{PM}_{2.5}$ concentrations were higher at heights of 6.5 and $10.5 \mathrm{~m}$, but lower at a height of $14.5 \mathrm{~m}$, compared to the daily concentrations $(p<0.05)$. The $\mathrm{PM}_{2.5}$ concentrations during the nucleation events were generally lower than the daily concentrations $(p<0.01)$.

At Building B, $N_{30-100}, N_{>100}$ and $\mathrm{PM}_{2.5}$ concentration at street levels were always higher than those at rooftop levels $(p<0.05)$. The daily and rush-hour TNCs were significantly higher at street level compared to those at rooftop level, but the opposite was the case during the nucleation events $(p<0.05) . N_{<30}$ at rooftop level was significantly higher than at street level during the nucleation event $(p<0.01)$, while their daily and rush-hour concentrations were relatively similar (p-values of 0.17 and 0.78 , respectively).

The daily PNSD and $\mathrm{PM}_{2.5}$ concentration decreased with height between 1.5 and $21.5 \mathrm{~m}$ at the rear (opposite side facing the road) of Building $\mathrm{C}(p<0.01)$, however $N_{30-100}$, $N_{>100}, \mathrm{PM}_{2.5}$ tended to stabilise at heights between 5.5 and $9.5 \mathrm{~m}$, followed by a less pronounced decrease from 9.5 to $21.5 \mathrm{~m}$. During the rush-hour periods, $N_{30-100}, N_{>100}$, TNC decreased from 1.5 to $9.5 \mathrm{~m}$, and then stabilised at heights between 9.5 and $21.5 \mathrm{~m} . N_{<30}$ increased at the beginning of the rush-hour period, then decreased from 5.5 to $9.5 \mathrm{~m}$, and finally stabilised onwards. The rush-hour $\mathrm{PM}_{2.5}$ followed the $\mathrm{PM}_{2.5}$ daily trends and was higher than the daily concentrations.

In general, the trend of TNC followed those of $N_{<30}$ and $N_{30-100}$ during the nucleation event and rush-hours, respectively, while the trends of $N_{>100}$ and $\mathrm{PM}_{2.5}$ were similar.

At Building B, the daily and rush-hour PN concentrations at street level were higher than those on the rooftop. This finding is in agreement with the results of previous studies (Hitchins et al., 2002; Kumar et al., 2009; Li et al., 2007; Longley et al., 2004; Väkevä et al., 1999). On the contrary, the daily and rush-hour PN concentrations at Building A increased with height. This is likely to be attributed to the fact that the busway is located close to the building and elevated above ground level, and therefore, it has a stronger influence on the concentrations measured at higher levels compared to Building B. The daily and rush-hour PN concentrations at the rear of Building $\mathrm{C}$ decreased with increasing height. This finding is not in agreement with the results reported by Hitchins et al. (2002) based on measurements in Brisbane, where a short time measurement (5 samples during $450 \mathrm{~s}$ for each level) was conducted. The difference could be due to the highly diurnal variations of influencing factors, such as vehicle emissions, wind speed and wind direction on particle concentrations between the different levels of this building.

The $\mathrm{PM}_{2.5}$ concentrations seemed to consistently decrease with height throughout the day and this finding is also in accordance with previous research (Chan and Kwok, 2000; Horvath et al., 1988; Micallef and Colls, 1998; Rubino et al., 1998). However, the $\mathrm{PM}_{2.5}$ concentrations at Buildings $\mathrm{A}$ and $\mathrm{C}$ did not decrease consistently. In the case of the Building A, this may be due to the influence of the proximity of the busway. The sampling points were located on the rear side of Building $\mathrm{C}$ and were obstructed by other buildings located behind it, and therefore, some stagnation of air in this region may have influenced the $\mathrm{PM}_{2.5}$ concentrations at mid-height levels.

In general, the vertical profiles of the $\mathrm{PM}_{2.5}$ concentrations around the building envelopes decreased with increasing height. However, vertical profiles of the PNSD were building-specific and the rate of change with height was different at all three buildings. The results indicate that it is not only vehicle emissions that influence the particle vertical profiles, but new particle formation as well; while particle number increased, we observed a reduction in particle mass during the nucleation events. These results serve to further define the specific effect of roadway proximity and nucleation formation on the vertical profiles of $\mathrm{PN}$ and $\mathrm{PM}_{2.5}$ concentrations around building envelopes. Moreover, the highly building-specific nature of the profiles and factors affecting them underscores that, ideally, measurements form the basis of any modelling or planning exercise prior to or after construction of a building. Such an approach, which is currently lacking for the most part, will ensure the greatest model veracity. This has important implications for selecting appropriate sites for the air intakes of building HVAC systems to minimise occupant exposure to combustion products, and also to investigate how street-level exposures may be mitigated via improved design practices.

\subsection{Relationship between PNSD and $\mathbf{P M}_{2.5}$ concentration}

Spearman's correlation coefficients $(\rho)$ for the PNSD and $\mathrm{PM}_{2.5}$ concentrations at different heights and different time periods at Buildings A, B and C are presented in Figs. 13, 14, 15 , respectively, and Table S2. However, as noted, new particle formation data was collected only at the reference site and street level during the measurement campaign of Building $\mathrm{C}$. Therefore, correlations between the PNSD and $\mathrm{PM}_{2.5}$ during the nucleation events at this site were not calculated. In general, the correlation coefficients between $N_{>100}$ and $\mathrm{PM}_{2.5}$ were higher, while the correlation coefficients of $N_{<30}$ were usually lower compared to other particle size fractions.

The PNSD and $\mathrm{PM}_{2.5}$ correlation coefficients on the rooftop were higher than those at street level at Building B. The difference between correlation coefficients for PN size fractions and $\mathrm{PM}_{2.5}$ concentrations at Building A were 


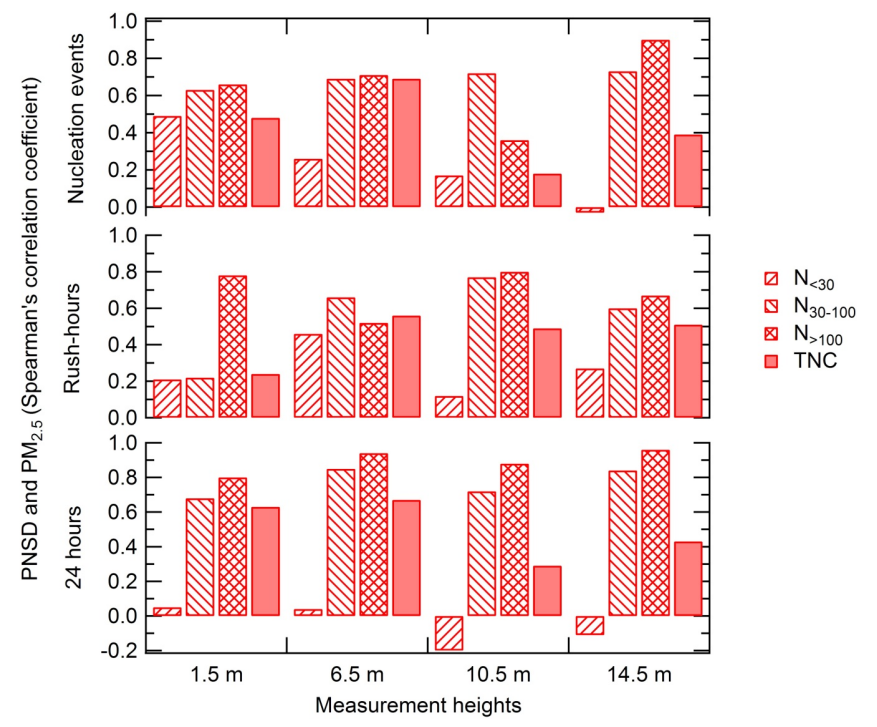

Fig. 13. Relationship between $\mathrm{PNSD}$ and $\mathrm{PM}_{2.5}$ at different heights for Building A.

higher than at Building B. This is likely due to the relative proximity of the particle sources at each level, as well as to the closeness to the busway at Building A. Both daily and rush-hour correlation coefficients of PNSD at the rear of Building C initially increased from the ground to level 3, and then decreased closer to the rooftop.

Correlations between the PNSD and $\mathrm{PM}_{2.5}$ were characterised by a significant variability and dependence on particle size fraction, measured height and particle emission sources. The linear correlations for the building envelopes, especially during the rush-hour and nucleation events, fluctuated significantly. This indicates that it is not appropriate to use particle mass concentrations to infer PN concentrations when modelling vertical concentrations around the building envelope and at a street level. This finding, while not a novel observation, adds weight to the existing case for separately considering particle mass and number during any urban modelling or exposure assessment exercise.

\section{Conclusions}

In general, vertical profiles of $\mathrm{PM}_{2.5}$ concentrations around building envelopes showed a consistent decrease in concentration with increasing distance from nearby streets. However, vertical profiles of PN size fraction concentrations were building-specific and its rate of change was inconsistent with height. These results are not unexpected, in view of the complex flow patterns around the building envelopes, as well as in the busway and street canyons proximate to some of the buildings. The results of simultaneous measurements indicated that it was not only vehicle emissions but new particle formation was also found to strongly influence the vertical

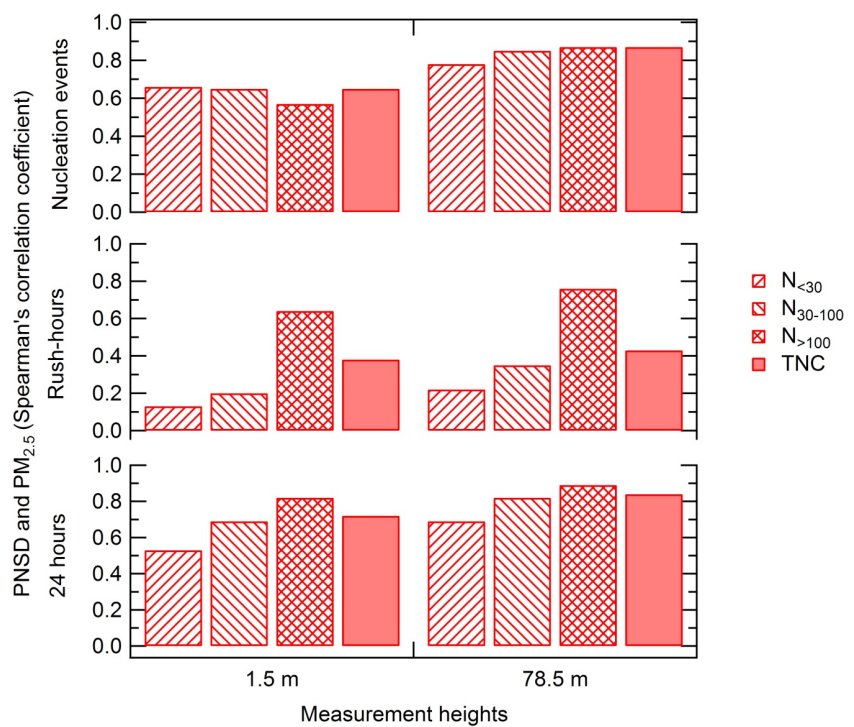

Fig. 14. Relationship between $\mathrm{PNSD}$ and $\mathrm{PM}_{2.5}$ at different heights for Building B.

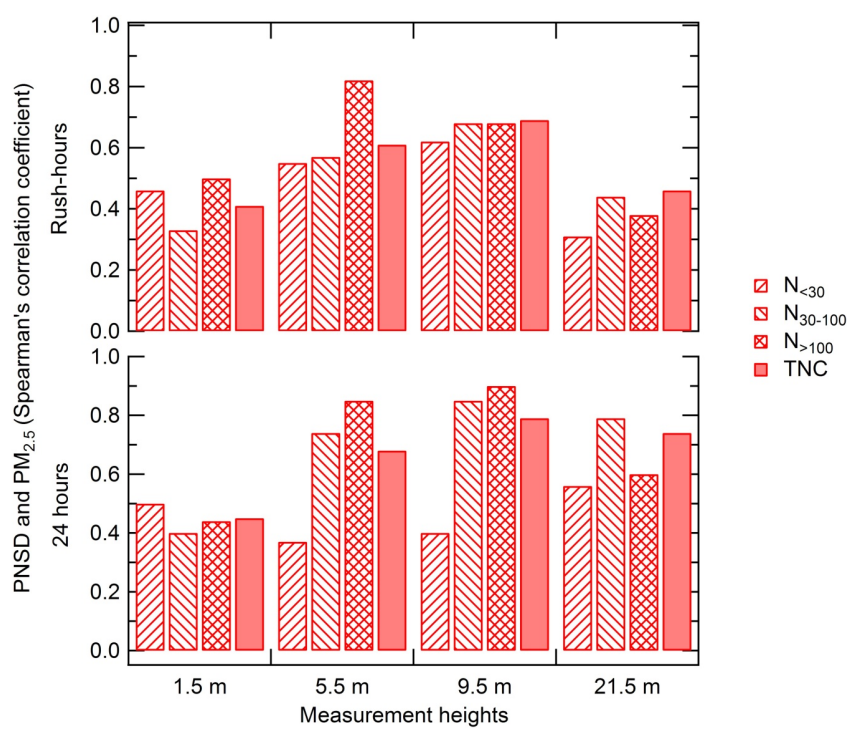

Fig. 15. Relationship between $P N S D$ and $\mathrm{PM}_{2.5}$ at different heights for Building $\mathrm{C}$.

profiles of particle concentrations. Time series ratios of PN and $\mathrm{PM}_{2.5}$ concentrations at street and rooftop levels showed clearly diurnal variation. These suggest that it is impossible to generalise vertical profiles of particle concentrations for all buildings, and that there is a need to conduct measurements or model these vertical profiles for a specific case when planning building morphology and air intake locations. Furthermore, newly formed particles and building-scale variability should also be into account when modelling particle concentrations around the building envelope, and also for urban 
environments and the exposures that occur within them in general.

The results of this serve to provide better insight into the impact of nucleation and local scale variability on particle concentrations, and will also help to better define particle behaviour and variability around building envelopes, which has implications for studies of both human exposure and particle dynamics.

\section{Supplementary material related to this article is available online at: http://www.atmos-chem-phys.net/12/ 5017/2012/acp-12-5017-2012-supplement.pdf.}

Acknowledgements. This project was funded by the Queensland Department of Public Works, and the Australian Research Council, through ARC Linkage Grant LP0776542. We would also like to thank the building managers and the security staff at the buildings we investigated and Rachael Appleby from the International Laboratory for Air Quality and Health, for assisting us during the project implementation.

Edited by: V.-M. Kerminen

\section{References}

Boy, M. and Kulmala, M.: Nucleation events in the continental boundary layer: Influence of physical and meteorological parameters, Atmos. Chem. Phys., 2, 1-16, doi:10.5194/acp-2-1-2002, 2002.

Bullin, J. A., Bower, S. C., Hinz, M., and Moe, R. D.: Aerosols near urban street intersections, J. Air Pollut. Contr. Assoc., 35, 355-358, 1985.

Chan, L. Y. and Kwok, W. S.: Vertical dispersion of suspended particulates in urban area of Hong Kong, Atmos. Environ., 34, 4403-4412, 2000.

Chen, M. L. and Mao, I. F.: Spatial variations of airborne particles in metropolitan Taipei, Sci. Total Environ., 209, 225-231, 1998.

Cheung, H. C., Morawska, L., and Ristovski, Z. D.: Observation of new particle formation in subtropical urban environment, Atmos. Chem. Phys., 11, 3823-3833, doi:10.5194/acp-11-38232011, 2011.

Dal Maso, M., Kulmala, M., Riipinen, I., Wagner, R., Hussein, T., Aalto, P. P., and Lehtinen, K. E. J.: Formation and growth of fresh atmospheric aerosols: eight years of aerosol size distribution data from SMEAR II, Hyytiala, Finland, Boreal Environ. Res., 10, 323-336, 2005.

Davidson, C. I., Phalen, R. F., and Solomon, P. A.: Airborne particulate matter and human health: A review, Aerosol Sci. Technol., 39, 737-749, doi:10.1080/02786820500191348, 2005.

Franck, U., Odeh, S., Wiedensohler, A., Wehner, B., and Herbarth, O.: The effect of particle size on cardiovascular disorders - The smaller the worse, Sci. Total Environ., 409, 4217-4221, 2011.

Gao, J., Wang, T., Zhou, X., Wu, W., and Wang, W.: Measurement of aerosol number size distributions in the Yangtze River delta in China: Formation and growth of particles under polluted conditions, Atmos. Environ., 43, 829-836, 2009.
Harrison, R. M., Jones, M., and Collins, G.: Measurements of the physical properties of particles in the urban atmosphere, Atmos. Environ., 33, 309-321, 1999.

He, M. and Dhaniyala, S.: Vertical and horizontal concentration distributions of ultrafine particles near a highway, Atmos. Environ., 46, 225-236, 2012.

Hitchins, J., Morawska, L., Gilbert, D., and Jamriska, M.: Dispersion of particles from vehicle emissions around high- and lowrise buildings, Indoor Air-Int. J. Indoor Air Qual. Clim., 12, 6471, 2002.

Horvath, H., Kreiner, I., Norek, C., Preining, O., and Georgi, B.: Diesel emissions in Vienna, Atmos. Environ., 22, 1255-1269, 1988.

Hussein, T., Martikainen, J., Junninen, H., Sogacheva, L., Wagner, R., Dal Maso, M., Riipinen, I., Aalto, P. P., and Kulmala, M.: Observation of regional new particle formation in the urban atmosphere, Tellus B, 60, 509-521, doi:10.1111/j.16000889.2008.00365.x, 2008.

Imhof, D., Weingartner, E., Vogt, U., Dreiseidler, A., Rosenbohm, E., Scheer, V., Vogt, R., Nielsen, O. J., Kurtenbach, R., Corsmeier, U., Kohler, M., and Baltensperger, U.: Vertical distribution of aerosol particles and $\mathrm{NO}_{\mathrm{x}}$ close to a motorway, Atmos. Environ., 39, 5710-5721, doi:10.1016/j.atmosenv.2004.07.036, 2005.

Kalaiarasan, M., Balasubramanian, R., Cheong, K. W. D., and Tham, K. W.: Traffic-generated airborne particles in naturally ventilated multi-storey residential buildings of Singapore: Vertical distribution and potential health risks, Build. Environ., 44, 1493-1500, 2009.

Kumar, P., Fennell, P. S., Hayhurst, A. N., and Britter, R. E.: Street Versus Rooftop Level Concentrations of Fine Particles in a Cambridge Street Canyon, Bound.-Lay. Meteorol., 131, 3-18, doi:10.1007/s10546-008-9300-3, 2009.

Leuzzi, G. and Monti, P.: Particle trajectory simulation of dispersion around a building, Atmos. Environ., 32, 203-214, doi:10.1016/S1352-2310(97)00291-4, 1998.

Li, X. L., Wang, J. S., Tu, X. D., Liu, W., and Huang, Z.: Vertical variations of particle number concentration and size distribution in a street canyon in Shanghai, China, Sci. Total Environ., 378, 306-316, doi:10.1016/j.scitotenv.2007.02.040, 2007.

Longley, I. D., Gallagher, M. W., Dorsey, J. R., Flynn, M., Allan, J. D., Alfarra, M. R., and Inglis, D.: A case study of aerosol $(4.6 \mathrm{~nm}<\mathrm{Dp}<10 \mu \mathrm{m})$ number and mass size distribution measurements in a busy street canyon in Manchester, UK, Atmos. Environ., 37, 1563-1571, doi:10.1016/S1352-2310(03)00010-4, 2003.

Longley, I. D., Gallagher, M. W., Dorsey, J. R., Flynn, M., Bower, K. N., and Allan, J. D.: Street canyon aerosol pollutant transport measurements, Sci. Total Environ., 334-335, 327-336, doi:10.1016/j.scitotenv.2004.04.072, 2004.

Mejía, J. F. and Morawska, L.: An investigation of nucleation events in a coastal urban environment in the Southern Hemisphere, Atmos. Chem. Phys., 9, 7877-7888, doi:10.5194/acp-9-7877-2009, 2009.

Micallef, A. and Colls, J. J.: Variation in airborne particulate matter concentration over the first three metres from ground in a street canyon: Implications for human exposure, Atmos. Environ., 32, 3795-3799, 1998. 
Morawska, L., Ristovski, Z., Jayaratne, E. R., Keogh, D. U., and Ling, X.: Ambient nano and ultrafine particles from motor vehicle emissions: Characteristics, ambient processing and implications on human exposure, Atmos. Environ., 42, 8113-8138, doi:10.1016/j.atmosenv.2008.07.050, 2008.

O’Dowd, C., McFiggans, G., Creasey, D. J., Pirjola, L., Hoell, C., Smith, M. H., Allan, B. J., Plane, J. M. C., Heard, D. E., and Lee, J. D.: On the photochemical production of new particles in the coastal boundary layer, Geophys. Res. Lett., 26, 1707-1710, 1999.

Oberdorster, G.: Toxicology of ultrafine particles: in vivo study, Philos. T. R. Soc. Lond., 358, 2719-2740, 2000.

Park, K., Park, J. Y., Kwak, J.-H., Cho, G. N., and Kim, J.-S.: Seasonal and diurnal variations of ultrafine particle concentration in urban Gwangju, Korea: Observation of ultrafine particle events, Atmos. Environ., 42, 788-799, doi:10.1016/j.atmosenv.2007.09.068, 2008.

Perez, N., Pey, J., Cusack, M., Reche, C., Querol, X., Alastuey, A., and Viana, M.: Variability of Particle Number, Black Carbon, and $\mathrm{PM}_{10}, \mathrm{PM}_{2.5}$, and $\mathrm{PM}_{1}$ Levels and Speciation: Influence of Road Traffic Emissions on Urban Air Quality, Aerosol Sci. Technol., 44, 487-499, doi:10.1080/02786821003758286, 2010.

Pey, J., Rodriguez, S., Querol, X., Alastuey, A., Moreno, T., Putaud, J. P., and Van Dingenen, R.: Variations of urban aerosols in the western Mediterranean, Atmos. Environ., 42, 9052-9062, doi:10.1016/j.atmosenv.2008.09.049, 2008.

Pey, J., Querol, X., Alastuey, A., Rodriguez, S., Putaud, J. P., and Van Dingenen, R.: Source apportionment of urban fine and ultra-fine particle number concentration in a Western Mediterranean city, Atmos. Environ., 43, 4407-4415, doi:10.1016/j.atmosenv.2009.05.024, 2009.
Pope, C. A.: Review: Epidemiological basis for particulate air pollution health standards, Aerosol Sci. Technol., 32, 4-14, 2000.

Qian, S., Sakurai, H., and McMurry, P. H.: Characteristics of regional nucleation events in urban East St. Louis, Atmos. Environ., 41, 4119-4127, doi:10.1016/j.atmosenv.2007.01.011, 2007.

Rubino, F. M., Floridia, L., Tavazzani, M., Fustinoni, S., Giampiccolo, R., and Colombi, A.: Height profile of some air quality markers in the urban atmosphere surrounding a $100 \mathrm{~m}$ tower building, Atmos. Environ., 32, 3569-3580, 1998.

Salma, I., Borsós, T., Weidinger, T., Aalto, P., Hussein, T., Dal Maso, M., and Kulmala, M.: Production, growth and properties of ultrafine atmospheric aerosol particles in an urban environment, Atmos. Chem. Phys., 11, 1339-1353, doi:10.5194/acp-111339-2011, 2011.

Schwartz, J. and Neas, L. M.: Fine particles are more strongly associated than coarse particles with acute respiratory health effects in schoolchildren, Epidemiology, 11, 6-10, 2000.

Stanier, C. O., Khlystov, A. Y., and Pandis, S. N.: Nucleation events during the Pittsburgh air quality study: Description and relation to key meteorological, gas phase, and aerosol parameters, Aerosol Sci. Technol., 38, 253-264, doi:10.1080/02786820390229570, 2004.

Väkevä, M., Hämeri, K., Kulmala, M., Lahdes, R., Ruuskanen, J., and Laitinen, T.: Street level versus rooftop concentrations of submicron aerosol particles and gaseous pollutants in an urban street canyon, Atmos. Environ., 33, 1385-1397, 1999.

Zhu, Y. and Hinds, W. C.: Predicting particle number concentrations near a highway based on vertical concentration profile, Atmos. Environ., 39, 1557-1566, doi:10.1016/j.atmosenv.2004.11.015, 2005. 